\title{
Overexpression of CXCR7 induces angiogenic capacity of human hepatocellular carcinoma cells via the AKT signaling pathway
}

\author{
YUHUI CHEN* ${ }^{*}$ FEI TENG* , GEYING WANG and ZHIYU NIE \\ Department of Neurology, Shanghai Tongji Hospital, Tongji University School of Medicine, Shanghai 200065, P.R. China
}

Received March 29, 2016; Accepted August 8, 2016

DOI: $10.3892 /$ or.2016.5045

\begin{abstract}
Angiogenesis is essential for tumor growth, especially in hepatocellular carcinoma (HCC). The hypervascularity is associated with poor prognosis and highly invasive HCC. The C-X-C chemokine receptor type 7 (CXCR7) has been implied overexpressed in many tumor types. Our study aimed to investigate the CXCR7 function in HCC. The tube formation, Transwell migration assay of human umbilical vein endothelial cells (HUVECs) and chicken chorioallantoic membrane (CAM) assay were used. We confirmed that CXCR7 induces angiogenic capacity. Moreover, overexpressing CXCR7 increased the phosphorylated (but not total) AKT expression in HCC cells. Furthermore, overexpressing CXCR7 increased the expression of tumor necrosis factor (TNF)- $\alpha$, interleukin (IL)-6 and IL-8 in HCC cells. Additionally, inhibition of AKT by LY294002 abrogated CXCR7-induced angiogenic capacity in HCC cells. Our study suggested that CXCR7 plays an important pro-angiogenic role in $\mathrm{HCC}$ via activation of the AKT pathway. So CXCR7 may be a potential target for anti-angiogenic therapy in HCC.
\end{abstract}

\section{Introduction}

Angiogenesis, the creation of new blood vessels, is an important effector of many physiological and pathological processes (1). Angiogenesis occurs to induce tumor growth and metastasis, and represents a key hallmark of tumor development (2-5). Tumor angiogenesis provides the nutrients and oxygen to maintain tumor growth and invasion. Thus, inhibition of tumor angiogenesis may decrease tumor cell growth

Correspondence to: Dr Yuhui Chen, Department of Neurology, Shanghai Tongji Hospital, Tongji University School of Medicine, 389 Xincun Road, Shanghai 200065, P.R. China

E-mail: Lihuicheng1234@yeah.net

${ }^{*}$ Contributed equally

Key words: hepatocellular carcinoma, C-X-C chemokine receptor type 7, human umbilical vein endothelial cells, angiogenesis and spread (6-8). Angiogenesis is considered to be an effective therapeutic target; hence, angiogenesis is a necessary area of biological research and clinical oncology $(4,9,10)$. Tumor angiogenesis is an outcome of an imbalance between pro-angiogenic factors, including the vascular endothelial growth factor (VEGF) family, and anti-angiogenesis factors, such as endostatin and other related factors (11-13). VEGF effects the sprouting and endothelial cell proliferation, and then VEGF can stimulate tumor angiogenesis (14). Many of anti-angiogenesis drugs serve as inhibiting pro-angiogenic factors, such as the monoclonal antibody bevacizumab binds to VEGF, or other small molecules that inhibit the binding of VEGF $(15,16)$. Nevertheless, the mechanisms of tumor angiogenesis are not yet entirely understood and specific, effective inhibitors of angiogenesis are required for cancer therapy.

Hepatocellular carcinoma (HCC) includes $>90 \%$ of primary malignant liver cancers and is one of the most common reasons for cancer-related mortality $(17,18)$. Because of the hepatitis $\mathrm{B}$ virus (HBV) and hepatitis $\mathrm{C}$ virus (HCV) infection, the HCC incidence is increasing in Asia, especially in China (19). HCC is regarded as hypervascular, and tumor growth depends on angiogenesis $(15,20)$. Targeting angiogenesis by pharmacologic therapy has been used in many other solid tumors. Therefore, the anti-angiogenic strategy for HCC may increase the treatment outcomes for HCC patients.

C-X-C chemokine receptor type 7 (CXCR7), a new known orphan receptor, has been shown to bind stromal cell-derived factor-1 (SDF-1) (19,21). CXCR7 also has been demonstrated important for primordial germ cell migration in zebra fish (22). Recently, high level of CXCR7 has been confirmed to be associated with aggressive tumors (23). Moreover, overexpression of CXCR7 was found to be connected to metastatic recurrence in non-small cell lung cancer. Recently, overexpression of CXCR7 was reported in tumor cell lines and tissues (24). However, the CXCR7 function in angiogenesis of $\mathrm{HCC}$ is not yet clear.

We demonstrated that CXCR7 is highly expressed in HCC cell lines. In addition, overexpression of CXCR7 promoted the angiogenic capacity of HCC cells via ATK signaling pathway. This study demonstrates that CXCR7 may induce angiogenesis in vivo; therefore, CXCR7 may have potential therapeutic effects in HCC. 


\section{Materials and methods}

Cell lines. The HCC cell lines HCCLM3 (100\% lung metastatic potential), MHCC97-L (low metastatic potential) and SMMC-7721 (without lung metastatic potential) were purchased from the Chinese Academy of Science (Shanghai, China). The cells were cultured in Dulbecco's modified Eagle's medium (DMEM) supplemented with $10 \%$ fetal bovine serum (FBS) (both from Gibco, Carlsbad, CA, USA) and $100 \mathrm{U}$ penicillin-streptomycin (Invitrogen, Carlsbad, CA, USA) in a $5 \% \mathrm{CO}_{2}$ humidified incubator at $37^{\circ} \mathrm{C}$.

Real-time reverse transcription-PCR analyses. The CXCR7 mRNA expression was calculated as follows. Reactions were executed in $20 \mu \mathrm{l}$ volumes, every sample including $2 \mu \mathrm{l}$ complementary DNA (cDNA) by using the primer pairs: CXCR7 sense, 5'-GGGATGCAGCGGATAGTCAA-3' and antisense, 5'-CGGTCGTTGTCCACATCCA-3'; Taqman probe, 5'-TCGGTCTCTCCCTGCCCGTCCT-3'. Real-time reverse transcription-PCR used TaqMan PCR reagents and the ABI PRISM 7700 Sequence Detection System (Applied Biosystems, Foster City, CA, USA) followed with an initial denaturation step at $95^{\circ} \mathrm{C}$ for $10 \mathrm{~min}$, then 28 cycles of denaturation at $95^{\circ} \mathrm{C}$ for $60 \mathrm{sec}$, primer annealing at $58^{\circ} \mathrm{C}$ for $30 \mathrm{sec}$ and primer extension at $72^{\circ} \mathrm{C}$ for $30 \mathrm{sec}$, with a final extension step at $72^{\circ} \mathrm{C}$ for $5 \mathrm{~min}$.

Western blotting. Western blotting was performed by using the Bio-Rad Transfer Cell System (Bio-Rad, Mississauga, ON, Canada). Rabbit anti-human CXCR7 antibody (1:200; R\&D Systems, Inc., Minneapolis, MN, USA) followed by 1:3,000 horseradish peroxidase-conjugated goat anti-rabbit IgG F(ab')2 antibody (Jackson ImmunoResearch, West Grove, PA, USA) was used.

Overexpression of CXCR7 in HCC cells. The HCC cell line HCCLM3 was transformed with human full-length CXCR7 cDNA by using Lipofectamine 2000 (Invitrogen). The HCC cell line HCCLM3 transformed with an empty plasmid was used as a negative control. Stable cell lines expressing CXCR7 were selected with G418 (K1, $250 \mu \mathrm{g} / \mathrm{ml}$; TPC-1, $200 \mu \mathrm{g} / \mathrm{ml}$; and B-CPAP, $300 \mu \mathrm{g} / \mathrm{ml}$ ). The CXCR7 expression was evaluated by western blotting.

RNA interference (RNAi) in HCC cells. Downregulation of the expression of CXCR7 in HCCLM3 cells was performed using small interfering RNAs (siRNAs) as follows: siCXCR7-286, 5'-CGC UCU CCU UCA UUU ACA UdTdT-3' (at position 286); negative control siRNA, 5'-UUC UCC GAA CGU GUC ACG UTT-3'; glyceraldehyde 3-phosphate dehydrogenase (GAPDH) positive control siRNA, 5'-GUA UGA CAA CAG CCU CAA GTT-3'. siRNA transfection of HCCLM3 cells was performed using the protocol.

Human umbilical vein endothelial cell (HUVEC) tube formation assay. The HUVEC tube formation assay was performed as previously described. Firstly, $200 \mu \mathrm{l}$ Matrigel were placed into a 96-well plate for $30 \mathrm{~min}$ at $37^{\circ} \mathrm{C}$. HUVECs $\left(2 \times 10^{4}\right)$ in $200 \mu \mathrm{l}$ conditioned medium (CM) from indicated HCC cells were added to the well and incubated for $24 \mathrm{~h}$ at $37^{\circ} \mathrm{C}$. Images
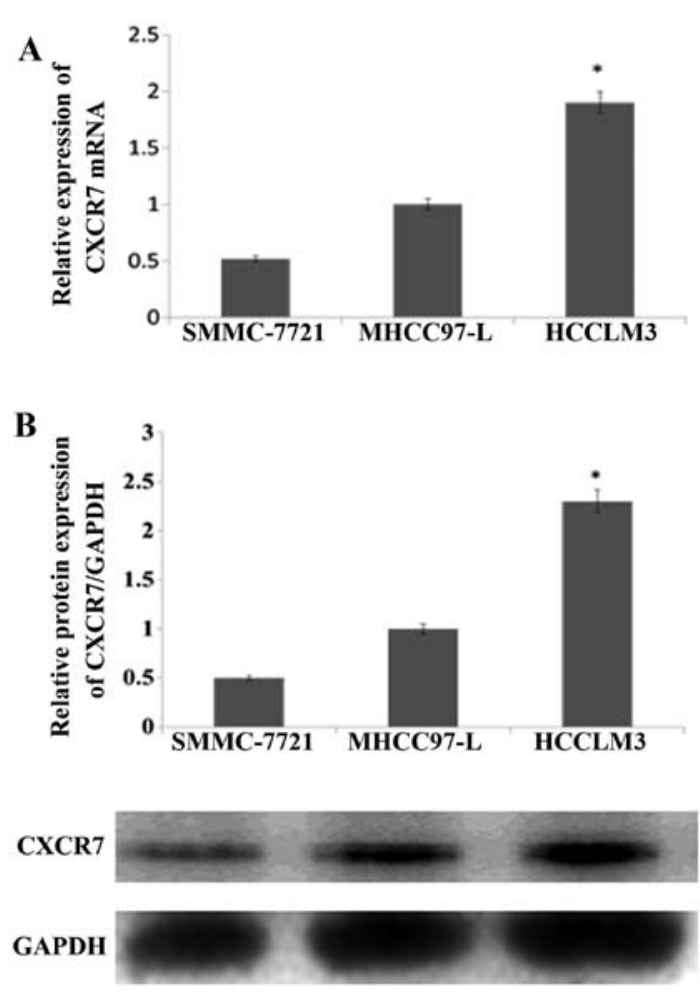

Figure 1. The CXCR7 expression in different metastatic HCC cell lines. (A) The mRNA expression of CXCR7 was examined by real-time PCR. (B) The protein expression of CXCR7 was determined by western blotting. Data are means \pm SD of three independent experiments. ${ }^{*} \mathrm{P}<0.05$. CXCR7, $\mathrm{C}-\mathrm{X}-\mathrm{C}$ chemokine receptor type 7 ; HCC, hepatocellular carcinoma.

were attained by a bright-field microscope (x100), and formation of capillary tubes was quantified by measuring their total number of each image.

Chicken chorioallantoic membrane (CAM) assay. The CAM assay was performed using 8-day-old chicken embryo. About $1-\mathrm{cm}$ diameter window was shaped in the shell of chicken embryo. A diameter gelatin sponge with $100 \mu \mathrm{l} \mathrm{CM}$ harvested from the indicated HCC cells was placed on the CAM. The windows in the chicken embryo were closed by bandages. The chicken embryos were incubated at $37^{\circ} \mathrm{C}$ for $48 \mathrm{~h}$. Then the CAM was fixed with stationary solution $(1: 1 \mathrm{v} / \mathrm{v}$ mixture of methanol and acetone) for $15 \mathrm{~min}$, the CAM was imaged by a digital camera. The number of second- and third-order vessels in the test samples was compared to control.

HUVEC Transwell migration assay. HUVECs $\left(1 \times 10^{4}\right)$ were cultured on the top of polycarbonate Transwell filters (pore size, $8.0 \mu \mathrm{m}$; Corning, Inc., Corning, NY, USA) in CM containing 5\% FBS. The lower chamber was filled with $500 \mu \mathrm{l}$ of media containing SDF- $1 \alpha(100 \mathrm{ng} / \mathrm{ml})$ and $15 \%$ FBS. The cells were incubated at $37^{\circ} \mathrm{C}$ for $8 \mathrm{~h}$, and the cells that migrated to the lower membrane surface were fixed in $4 \%$ paraformaldehyde, stained using hematoxylin for $15 \mathrm{~min}$, and the number of cells in 10 randomly selected x 200 fields of view per filter was counted and expressed relative to that of cells treated with CM from vector control cells.

Matrigel plug assay in mice. C57BL/6 mice were injected $50 \mu \mathrm{l}$ of reconstituted CM with $50 \mathrm{U} / \mathrm{ml}$ heparin and SDF- $1 \alpha$ 

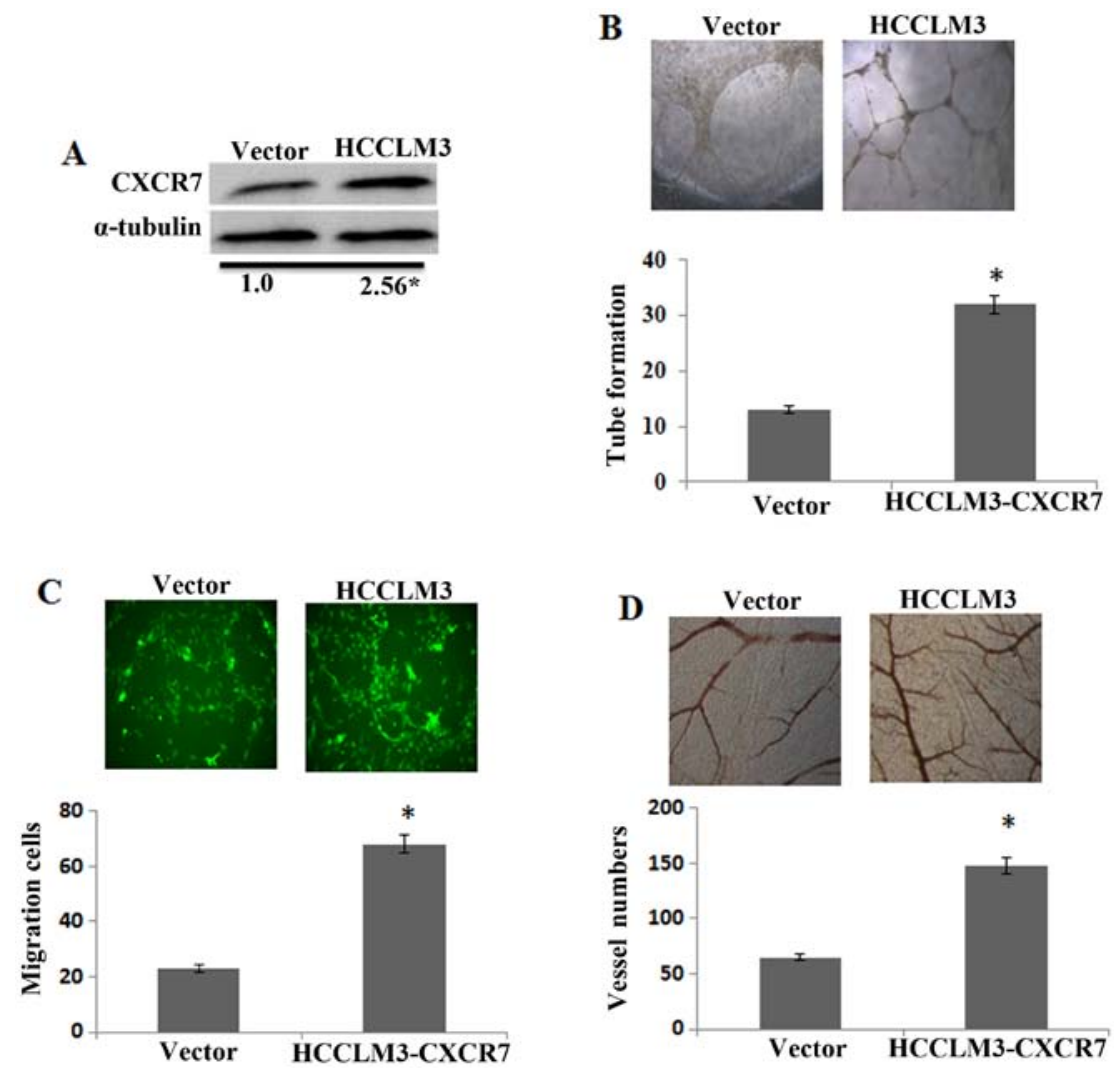

Figure 2. Overexpression of CXCR7 induces angiogenic capacity of HCC cells in vitro. (A) Western blotting of HCCLM3-vector, HCCLM3-CXCR7 protein expression in HCCLM3 cells; $\alpha$-tubulin was used as a control. The numbers show the relative level of protein compared to the control. (B) The images (left) and quantification (right) of tube formation by HUVECs cultured in CM. (C) The migration images and quantification of HUVECs after incubation in CM. (D) The images (left) and quantification (right) of blood vessels in the CAM assay when stimulated by CM. Data are means \pm SD of three independent experiments. ${ }^{*} \mathrm{P}<0.05$. CXCR7, C-X-C chemokine receptor type 7; HCC, hepatocellular carcinoma; HUVECs, human umbilical vein endothelial cells; CM, conditioned medium; CAM, chicken chorioallantoic membrane.

$(100 \mathrm{ng} / \mathrm{ml})$ added to $0.6 \mathrm{ml}$ Matrigel. Matrigel polymerizes to a solid gel at body temperature, and then the gel become vascularized after 10 days. The gel was removed, photographed, stained, and also diluted in water to measure the hemoglobin content by Drabkin's reagent kit (Sigma).

Enzyme-linked immunosorbent assay (ELISA). The tumor necrosis factor (TNF)- $\alpha$, interleukin (IL)- 6 and IL-8 ELISA assay were performed by the commercial kits. All samples were added to the 96 -well in triplicate, incubated at $36^{\circ} \mathrm{C}$ for $90 \mathrm{~min}$, washed, incubated with a specific anti-antibody (Cell Signaling Technology, Inc.) at $36^{\circ} \mathrm{C}$ for $1 \mathrm{~h}$, washed, incubated with secondary antibody at $36^{\circ} \mathrm{C}$ for $1 \mathrm{~h}$, and then substrate was added, incubated for $1 \mathrm{~h}$ and the absorbance values were read at OD450 by an ELISA plate reader.

Statistical analysis. All experimental data are presented as the mean \pm SD of three independent biological replicates. Statistical analyses were performed using SPSS 13.0 (IBM Corp., Armonk, NY, USA). Analysis of variance (ANOVA) was used to evaluate the significance of the differences between two groups. $\mathrm{P} \leq 0.05$ was considered statistically significant.

\section{Results}

CXCR7 is upregulated in HCC cell lines. Western blotting and qRT-PCR assays demonstrated CXCR7 protein and mRNA expression in HCCLM3 cells. The qRT-PCR showed that CXCR7 mRNA level was obviously increased in HCCLM3 compared to the SMMC-7721 (Fig. 1A). Consistent with the mRNA results, the protein level also was significantly upregulated in HCCLM3 compared to the SMMC-7721 (Fig. 1B). The data implied that CXCR7 is overexpressed in HCC cells.

Overexpression of CXCR7 promotes the angiogenic capacity in HCC cells. Firstly, overexpression of CXCR7 in the HCCLM3 was confirmed by western blotting (Fig. 2A). The effect of CXCR7 inducing angiogenesis in the HCCLM3 was investigated by tube formation assay. CM from CXCR7 overexpression in HCCLM3 notably induced the tube formation compared to the control (Fig. 2B). In addition, CXCR7 overexpressing in HCCLM3 significantly induced the HUVEC migration (Fig. 2C). Moreover, CM from CXCR7 overexpression of HCCLM3 cells increased the second- and third-order vessel number in the CAM (Fig. 2D). The results together indicated, that CXCR7 induced the angiogenesis capacity of HCCLM3 cells in vitro.

Silencing CXCR7 reduces the angiogenic capacity in HCC cells. To better confirm the effect of CXCR7 on angiogenesis in the HCC progression, CXCR7 was knocked down in the HCCLM3 cells and was confirmed by western blotting (Fig. 3A). Compared to the control, CM from CXCR7 knockdown cells decreased HUVEC tube formation (Fig. 3B) 

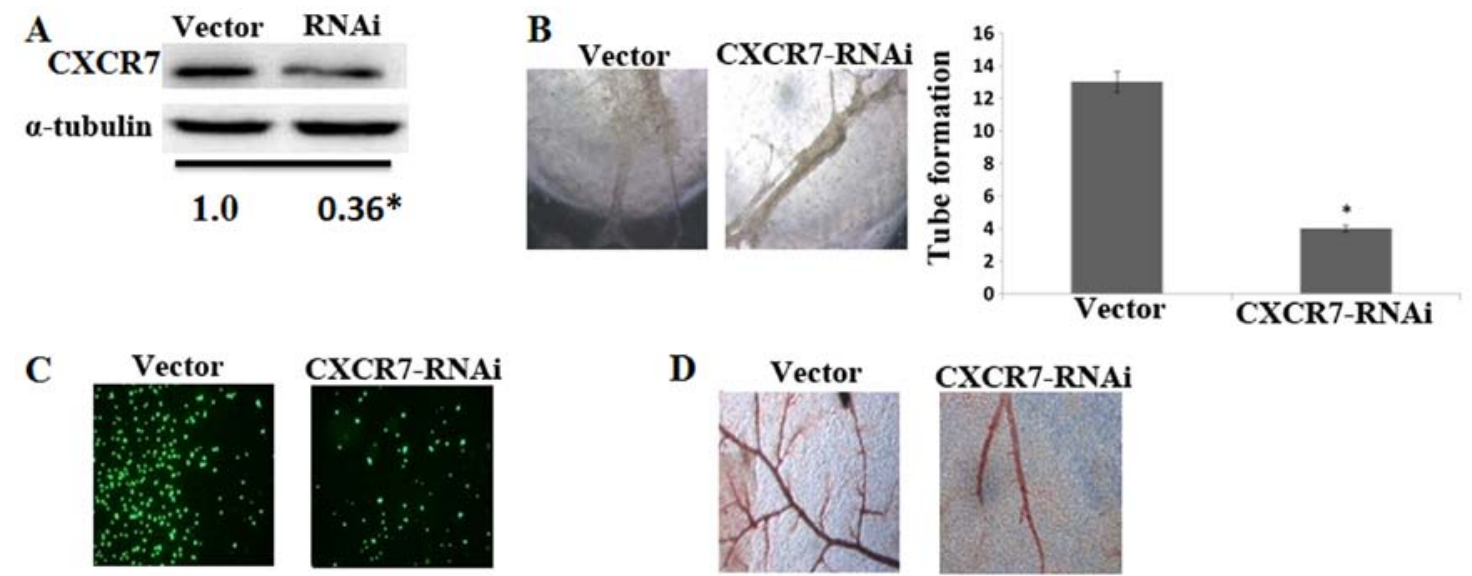

D
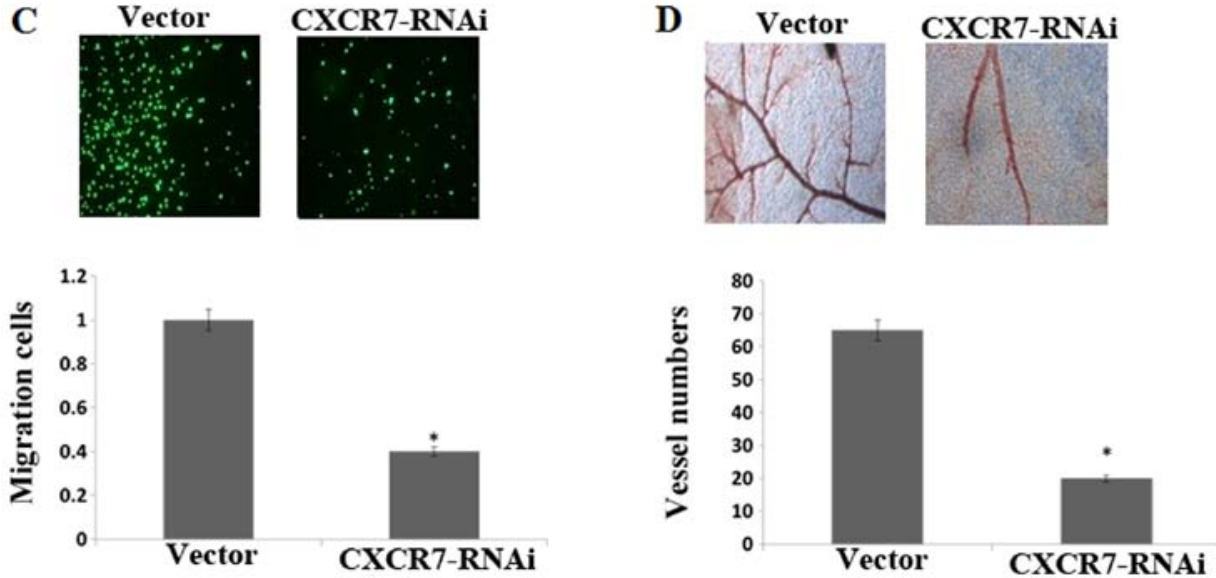

Figure 3. Knockdown of CXCR7 decreases the angiogenic capacity of HCC cells in vitro. (A) Western blotting of CXCR7-shRNA-transduced HCCLM3 protein expression in HCCLM3 cells; $\alpha$-tubulin was used as a control. The numbers show the relative level of protein compared to the control. (B) The images (left) and quantification (right) of tube formation by HUVECs cultured in CM. (C) The migration images and quantification of HUVECs after incubation in CM. (D) The images (left) and quantification (right) of blood vessels in the CAM assay when stimulated by CM. Data are means \pm SD of three independent experiments. "P<0.05. CXCR7, C-X-C chemokine receptor type 7; HCC, hepatocellular carcinoma; HUVECs, human umbilical vein endothelial cells; CM, conditioned medium; CAM, chicken chorioallantoic membrane.
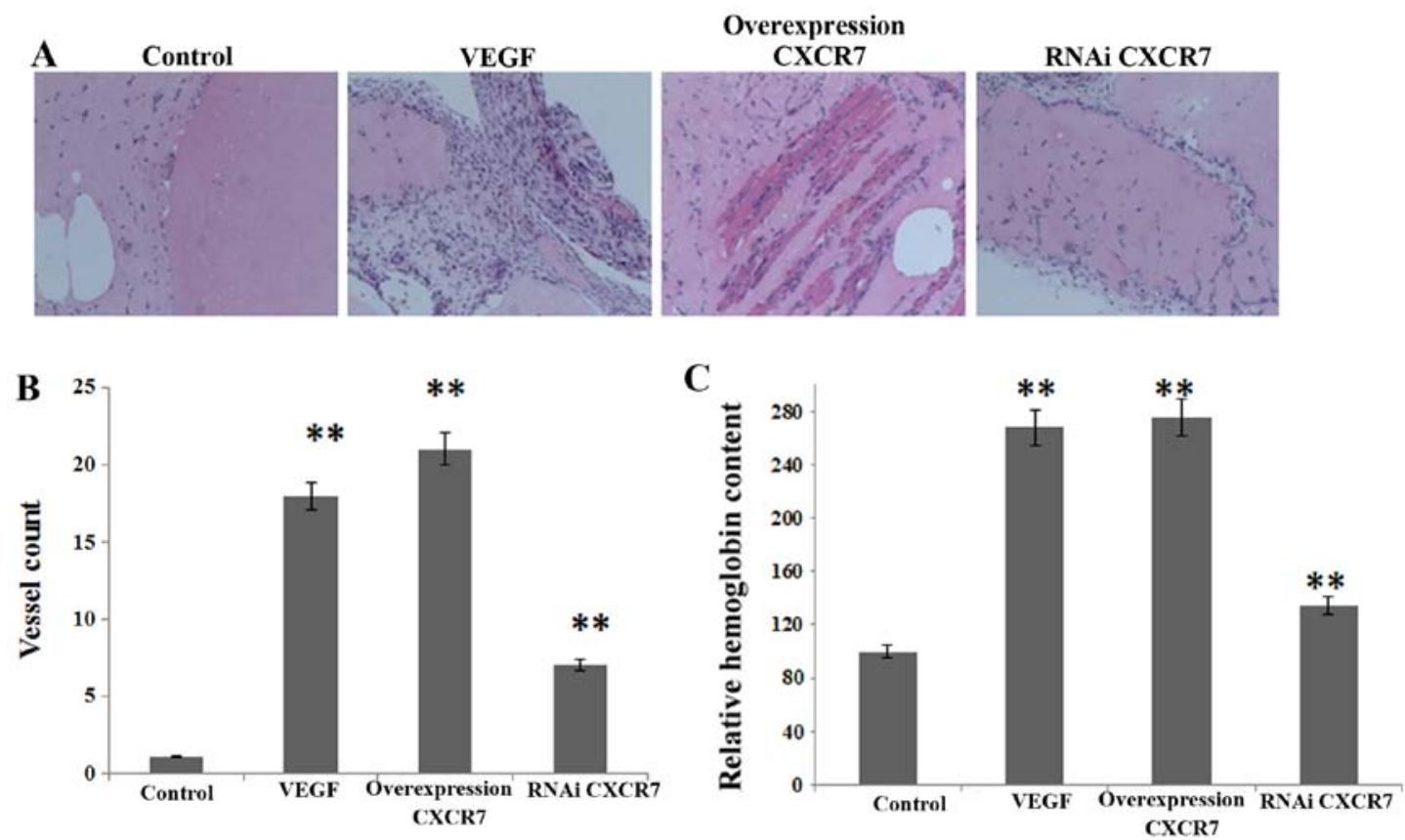

Figure 4. Matrigel plug assay of in vivo angiogenesis. (A) The images show vascularization of Matrigel plug under the various experimental conditions. (B) Matrigel plug assay was used quantitatively as vessel counts of the sponges under the various experimental conditions. (C) The relative Hb content of the plug under the various experimental conditions. Data are means $\pm \mathrm{SD}$ of three independent experiments. ${ }^{* *} \mathrm{P}<0.01$. Hb, hemoglobin.

and migration (Fig. 3C). CM from CXCR7 knockdown cells also decreased the second- and third-order vessel number in the CAM assay (Fig. 3D). These data illustrated that CXCR7 is involved in angiogenesis of HCCLM3 cells.
Overexpression of CXCR7 induces the angiogenic capacity in Matrigel plug assay. Vascularization was calculated by Matrigel plug assay (Fig. 4A). The C57BL/6 mice were injected with Matrigel containing aliquots of control, overexpressing 
A
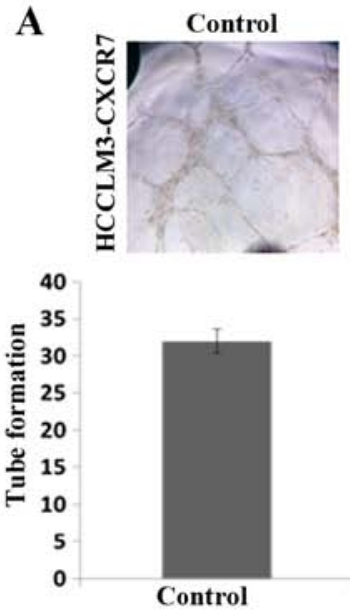

C
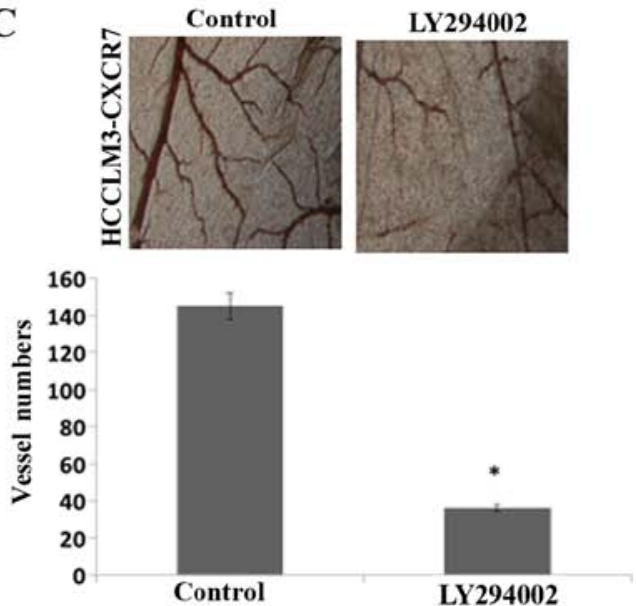

B

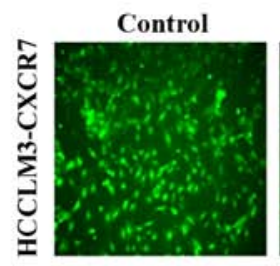

LY294002
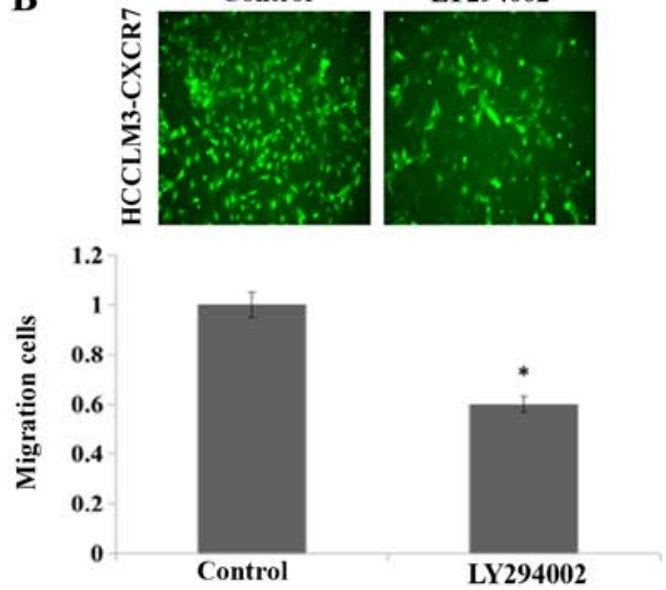

D
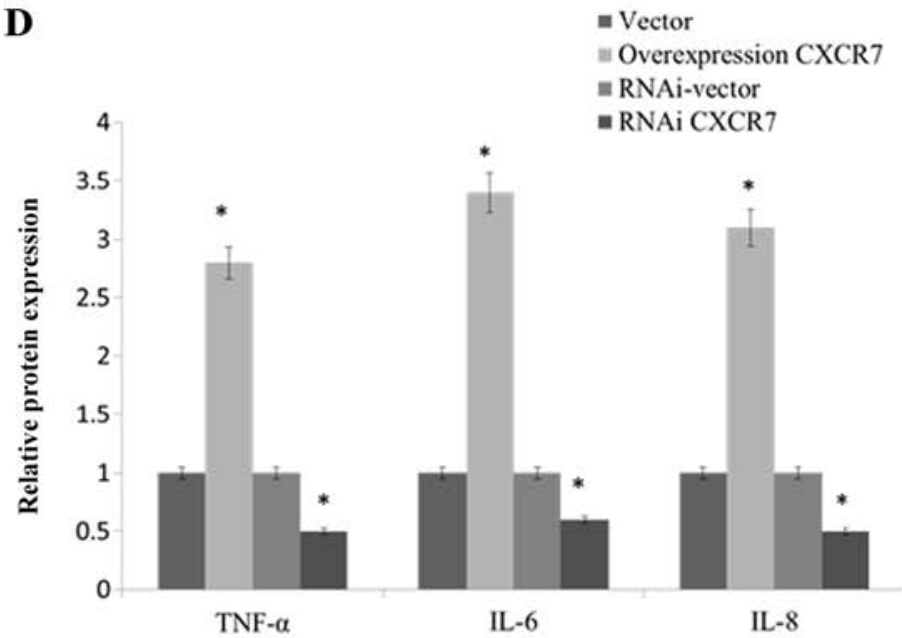

Figure 5. Overexpression of CXCR7 enhances the angiogenic capacity of HCC cells via activating the AKT pathway. CXCR7-overexpressing HCC cells were inhibited with LY294002, which uses as a specific AKT inhibitor. (A) The images and quantification of tube formation by HUVECs on CM from the indicated cells. (B) The migration images and quantification of HUVECs after incubation in CM. (C) The images and quantification of blood vessels in the CAM assay when stimulated by CM. (D) ELISA of TNF- $\alpha$, IL-6 and IL-8 protein expression in the indicated cells ${ }^{*} \mathrm{P}<0.05$. CXCR7, C-X-C chemokine receptor type 7; HCC, hepatocellular carcinoma; HUVECs, human umbilical vein endothelial cells; CM, conditioned medium; CAM, chicken chorioallantoic membrane; ELISA, enzyme-linked immunosorbent assay; TNF, tumor necrosis factor; IL, interleukin.

or silenced CXCR7 in HCCLM3, plus heparin $(50 \mathrm{U} / \mathrm{ml})$ and SDF-1 $\alpha(100 \mathrm{ng} / \mathrm{ml})$. As shown in Fig. 4B and C, the relative hemoglobin content and vessel number showed that angiogenesis was inhibited by CM containing CXCR7-silenced HCCLM3, whereas it was partially promoted by CM containing overexpressing CXCR7.

CXCR7 promotes the angiogenic capacity of HCC cells via activating the AKT signaling pathway. The CXCR7 affected the angiogenic capacity of HCCLM3 via activating AKT signaling. We used the AKT signaling inhibitor LY294002. The stimulatory effects of CM derived from CXCR7 overexpressing HCCLM3 on HUVEC tube formation (Fig. 5A), migration (Fig. 5B) and the second- and third-order vessel number in the CAM assay (Fig. 5C) was significantly reduced by using LY294002. Taken all together, these results suggested that CXCR7 enhances the angiogenic capacity of HCCLM3 cells via activation of the AKT signaling pathway. The expression of AKT target protein, including TNF- $\alpha$, IL- 6 and IL-8, was induced in CXCR7 overexpressing HCCLM3 and reduced in CXCR7 knockdown HCCLM3 (Fig. 5D). Moreover,

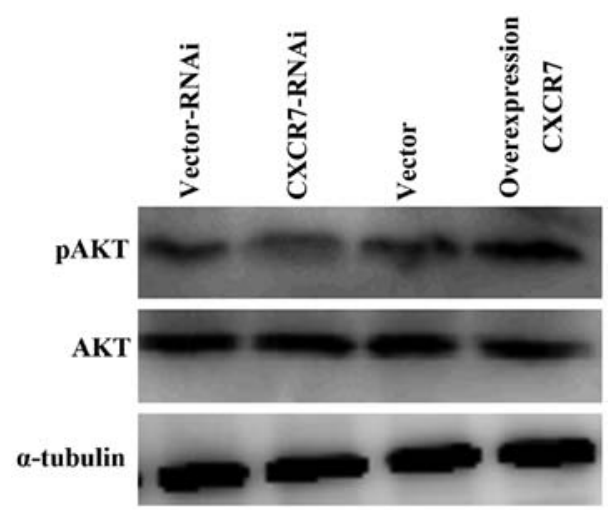

Figure 6. The protein expression analysis of the pAKT, total AKT; $\alpha$-tubulin was used as a loading control. Data are means \pm SD of three independent experiments. pAKT, phosphorylated AKT.

western blotting demonstrated that overexpression of CXCR7 upregulated the phosphorylated AKT expression but did not significantly impact the total AKT protein expression (Fig. 6). 
These data implied that the AKT pathway may trigger angiogenesis of CXCR7 in HCCLM3 cells.

\section{Discussion}

There is abundant evidence to show that CXCR7 overexpression is involved in HCC progress, including breast, lung, prostate and pancreatic cancers $(23,25)$. It has been demonstrated that knockdown of CXCR7 expression significantly reduces SMMC-7721 cell invasion, adhesion and angiogenesis. Moreover, decreased CXCR7 expression inhibited tumor growth in a mouse model of HCC. The highly specific CXCR7 antagonist CCX771 also was used. In the past report, CXCL12 induced Huh7, SNU449 and SNU475 cell migration, and the migration was blocked by CCX771/anti-CXCR7. Similarly, the CCX771 significantly inhibited glioma cell proliferation and invasion (26). The study provides new insights into the significance of CXCR7 in invasion and angiogenesis of tumors $(27,28)$. Although the study shows the importance of CXCR7 in HCC invasion, angiogenesis and tumor growth, the role of CXCR7 effect the HUVEC function in tumor microenvironment is not fully established. In the present study, CXCR7 was confirmed to be involved in metastatic HCC. Both the past studies and our data showed overexpression of CXCR7 in a highly metastatic HCC. Also, increased expression of CXCR7 in HCCLM3 induced the angiogenic capacity in vitro. Furthermore, silence of CXCR7 decreased the angiogenic capacity of HUVECs. The data showed that CXCR7 may induce angiogenesis via activating the AKT signaling pathway. Collectively the findings suggested the potential effect of CXCR7 in angiogenic capacity of HCC cells.

The overexpression of CXCR7 suggested several potential unknown functions. Although substantial research has suggested that CXCR7 may serve as an oncogene in many tumor types, the molecular mechanism of CXCR7 has not been accurately demonstrated. In our study, we found that the overexpression of CXCR7 induced the tube formation and migration of HUVECs and significantly induced the second- and third-order vessel number of CAM. The data showed the potential effect of CXCR7 angiogenic activities in HCC cells. Furthermore, overexpression of CXCR7 notably enhanced the AKT pathway activity, suggesting that phosphorylated AKT plays a key role in the CXCR7-induced angiogenesis of HCC progression. AKT signaling pathway is known to regulate inflammatory responses, and other physiological and pathological functions including cancer progression. The findings suggested that CXCR7 induces HCC angiogenesis via activating the AKT signaling pathway.

Additionally, overexpression of CXCR7 induced TNF- $\alpha$, IL-6, and IL-8 expression. TNF- $\alpha$ promoted angiogenesis and regulated blood vessel remodeling in vivo; IL-6 and IL-8 also promoted VEGF expression and tumor angiogenesis. Increasing and compelling epidemiological evidence has been suggested that the inflammatory microenvironment plays a key role in tumor cell proliferation, angiogenesis and metastasis (29-31). TNF- $\alpha$ is known as a key regulator of inflammation-related cancer, including HCC (32). IL-6 is necessary for HCC progression in animal models, with hepatic-associated macrophages representing a major paracrine IL- 6 expression during HCC development and autocrine IL-6 inducing notably HCC initiation (33-35). IL-8 induced HCC grade, metastasis and recurrence $(36,37)$. It would be worth exploring the TNF- $\alpha$, IL-6, and IL-8 functions in HCC angiogenesis. The TNF- $\alpha$, IL-6, and IL-8 expression in HCC cells remained to be clarified and should be investigated further.

In conclusion, our study indicated that CXCR7 is upregulated and induces angiogenic capacity in HCC by activation of the AKT pathway. These data may give new insight into the angiogenesis mechanism in HCC; and CXCR7 may be a new therapeutic target for HCC.

\section{Acknowledgements}

This study was supported by grants (grant nos. 81400961 and 81301157) of the National Natural Science Foundation of China (NSFC).

\section{References}

1. Carmeliet P: Angiogenesis in life, disease and medicine. Nature 438: 932-936, 2005.

2. Folkman J: Role of angiogenesis in tumor growth and metastasis. Semin Oncol 29 (Suppl 16): 15-18, 2002.

3. Varinska L, Gal P, Mojzisova G, Mirossay L and Mojzis J: Soy and breast cancer: Focus on angiogenesis. Int J Mol Sci 16: 11728-11749, 2015.

4. Herbst RS and Fidler IJ: Angiogenesis and lung cancer: Potential for therapy. Clin Cancer Res 6: 4604-4606, 2000.

5. Onishi M, Ichikawa T, Kurozumi K and Date I: Angiogenesis and invasion in glioma. Brain Tumor Pathol 28: 13-24, 2011.

6. Pollitt MJ, Hanby AM, Horgan K, Murphy CE, Jones PF and Speirs V: Angiogenesis in breast cancer: How should we measure this? (Review). Oncol Rep 13: 931-936, 2005.

7. Herbst RS, Onn A and Sandler A: Angiogenesis and lung cancer: Prognostic and therapeutic implications. J Clin Oncol 23: 3243-3256, 2005.

8. Sato Y: Molecular diagnosis of tumor angiogenesis and anti-angiogenic cancer therapy. Int J Clin Oncol 8: 200-206, 2003.

9. van Hinsbergh VW, Collen A and Koolwijk P: Angiogenesis and anti-angiogenesis: Perspectives for the treatment of solid tumors. Ann Oncol 10 (Suppl 4): 60-63, 1999.

10. Duarte IG, Bufkin BL, Pennington MF, Gal AA, Cohen C, Kosinski AS, Mansour KA and Miller JI: Angiogenesis as a predictor of survival after surgical resection for stage I non-small-cell lung cancer. J Thorac Cardiovasc Surg 115: 652-658, discussion 658-659, 1998.

11. Folkman J: Endogenous inhibitors of angiogenesis. Harvey Lect 92: 65-82, 1996-1997.

12. Gyenge M, Amagase K, Kunimi S, Matsuoka R and Takeuchi K: Roles of pro-angiogenic and anti-angiogenic factors as well as matrix metalloproteinases in healing of NSAID-induced small intestinal ulcers in rats. Life Sci 93: 441-447, 2013.

13. Marjon PL, Bobrovnikova-Marjon EV and Abcouwer SF: Expression of the pro-angiogenic factors vascular endothelial growth factor and interleukin-8/CXCL8 by human breast carcinomas is responsive to nutrient deprivation and endoplasmic reticulum stress. Mol Cancer 3: 4, 2004.

14. Hellberg C, Ostman A and Heldin CH: PDGF and vessel maturation. Recent Results Cancer Res 180: 103-114, 2010.

15. Alfaro C, Suarez N, Gonzalez A, Solano S, Erro L, Dubrot J, Palazon A, Hervas-Stubbs S, Gurpide A, Lopez-Picazo JM, et al: Influence of bevacizumab, sunitinib and sorafenib as single agents or in combination on the inhibitory effects of VEGF on human dendritic cell differentiation from monocytes. Br J Cancer 100: 1111-1119, 2009.

16. Thompson Coon J, Hoyle M, Green C, Liu Z, Welch K, Moxham T and Stein K: Bevacizumab, sorafenib tosylate, sunitinib and temsirolimus for renal cell carcinoma: A systematic review and economic evaluation. Health Technol Assess 14: 1-184, iii-iv, 2010.

17. Willatt JM, Francis IR, Novelli PM, Vellody R, Pandya A and Krishnamurthy VN: Interventional therapies for hepatocellular carcinoma. Cancer Imaging 12: 79-88, 2012. 
18. Zhu AX, Duda DG, Sahani DV and Jain RK: HCC and angiogenesis: Possible targets and future directions. Nat Rev Clin Oncol 8: 292-301, 2011.

19. Burns JM, Summers BC, Wang Y, Melikian A, Berahovich R, Miao Z, Penfold ME, Sunshine MJ, Littman DR, Kuo CJ, et al: A novel chemokine receptor for SDF-1 and I-TAC involved in cell survival, cell adhesion, and tumor development. J Exp Med 203 2201-2213, 2006.

20. Finn RS and Zhu AX: Targeting angiogenesis in hepatocellular carcinoma: Focus on VEGF and bevacizumab. Expert Rev Anticancer Ther 9: 503-509, 2009.

21. Balabanian K, Lagane B, Infantino S, Chow KY, Harriague J, Moepps B, Arenzana-Seisdedos F, Thelen M and Bachelerie F: The chemokine SDF-1/CXCL12 binds to and signals through the orphan receptor RDC1 in T lymphocytes. J Biol Chem 280: 35760-35766, 2005.

22. Boldajipour B, Mahabaleshwar H, Kardash E, Reichman-Fried M, Blaser H, Minina S, Wilson D, Xu Q and Raz E: Control of chemokine-guided cell migration by ligand sequestration. Cell 132: 463-473, 2008.

23. Wang J, Shiozawa Y, Wang J, Wang Y, Jung Y, Pienta KJ, Mehra R, Loberg R and Taichman RS: The role of CXCR7/RDC1 as a chemokine receptor for CXCL12/SDF-1 in prostate cancer. J Biol Chem 283: 4283-4294, 2008.

24. Zheng K, Li HY, Su XL, Wang XY, Tian T, Li F and Ren GS: Chemokine receptor CXCR7 regulates the invasion, angiogenesis and tumor growth of human hepatocellular carcinoma cells. J Exp Clin Cancer Res 29: 31, 2010.

25. Iwakiri S, Mino N, Takahashi T, Sonobe M, Nagai S, Okubo K, Wada H, Date H and Miyahara R: Higher expression of chemokine receptor CXCR7 is linked to early and metastatic recurrence in pathological stage I nonsmall cell lung cancer. Cancer 115: 2580-2593, 2009.

26. Liu Y, Carson-Walter E and Walter KA: Targeting chemokine receptor CXCR7 inhibits glioma cell proliferation and mobility. Anticancer Res 35: 53-64, 2015.

27. Lin L, Han MM, Wang F, Xu LL, Yu HX and Yang PY: CXCR7 stimulates MAPK signaling to regulate hepatocellular carcinoma progression. Cell Death Dis 5: e1488, 2014.
28. Xue TC, Jia QA, Bu Y, Chen RX, Cui JF, Tang ZY and Ye SL: CXCR7 correlates with the differentiation of hepatocellular carcinoma and suppresses HNF4 $\alpha$ expression through the ERK pathway. Oncol Rep 32: 2387-2396, 2014

29. Balkwill $\mathrm{F}$ and Mantovani A: Inflammation and cancer: Back to Virchow? Lancet 357: 539-545, 2001.

30. Castello G, Scala S, Palmieri G, Curley SA and Izzo F: HCV-related hepatocellular carcinoma: From chronic inflammation to cancer. Clin Immunol 134: 237-250, 2010.

31. Karin M and Greten FR: NF-kappaB: Linking inflammation and immunity to cancer development and progression. Nat Rev Immunol 5: 749-759, 2005.

32. Feldmann M: Development of anti-TNF therapy for rheumatoid arthritis. Nat Rev Immunol 2: 364-371, 2002.

33. Maeda S, Hikiba Y, Sakamoto K, Nakagawa H, Hirata Y, Hayakawa Y, Yanai A, Ogura K, Karin M and Omata M: Ikappa $\mathrm{B}$ kinasebeta/nuclear factor-kappaB activation controls the development of liver metastasis by way of interleukin-6 expression. Hepatology 50: 1851-1860, 2009.

34. Naugler WE, Sakurai T, Kim S, Maeda S, Kim K, Elsharkawy AM and Karin M: Gender disparity in liver cancer due to sex differences in MyD88-dependent IL-6 production. Science 317: 121-124, 2007.

35. Park EJ,Lee JH,Yu GY,He G,Ali SR, Holzer RG, OsterreicherCH, Takahashi $\mathrm{H}$ and Karin M: Dietary and genetic obesity promote liver inflammation and tumorigenesis by enhancing IL-6 and TNF expression. Cell 140: 197-208, 2010.

36. Ren Y, Poon RT, Tsui HT, Chen WH, Li Z, Lau C, Yu WC and Fan ST: Interleukin-8 serum levels in patients with hepatocellular carcinoma: Correlations with clinicopathological features and prognosis. Clin Cancer Res 9: 5996-6001, 2003.

37. Welling TH, Fu S, Wan S, Zou W and Marrero JA: Elevated serum IL-8 is associated with the presence of hepatocellular carcinoma and independently predicts survival. Cancer Invest 30: 689-697, 2012. 